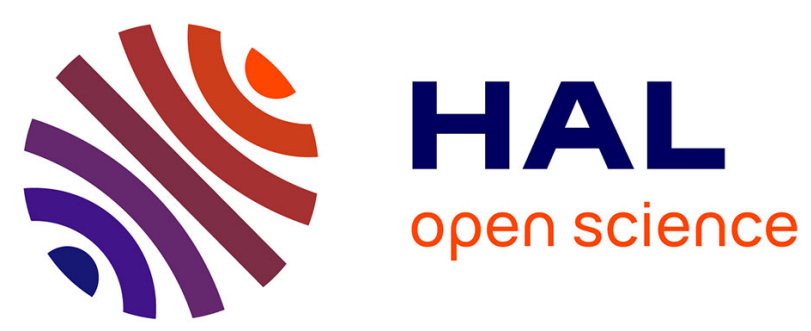

\title{
Values in Welfare economics
}

Antoinette Baujard

\section{To cite this version:}

Antoinette Baujard. Values in Welfare economics. 2021. halshs-03244909

\section{HAL Id: halshs-03244909 \\ https://shs.hal.science/halshs-03244909}

Preprint submitted on 1 Jun 2021

HAL is a multi-disciplinary open access archive for the deposit and dissemination of scientific research documents, whether they are published or not. The documents may come from teaching and research institutions in France or abroad, or from public or private research centers.
L'archive ouverte pluridisciplinaire HAL, est destinée au dépôt et à la diffusion de documents scientifiques de niveau recherche, publiés ou non, émanant des établissements d'enseignement et de recherche français ou étrangers, des laboratoires publics ou privés. 


\title{
GATE $_{\text {vonsuntrement }}$
}

UMR 5824

93. chemin des Mouilles 69130 Ecully - France

Maison de l'Université, Bâtiment B 10, rue Trefilerie 42023 Saint-Etienne cedex $02 \cdot$ France http://www.gate.cnrs.fr gate@gate.cnrs.fr

WP 2112 - June 2021

\section{Values in Welfare economics}

\section{Antoinette Baujard}

\begin{abstract}
:
This chapter focuses on the inner rationale and consequences of four different archetypal positions regarding how ethical and political values are tackled in welfare economics. Welfare economics is standardly associated with the welfarist framework, for which social welfare is based on individual utility only. Beyond this, we distinguish the value-neutrality claim - for which ethical values should be and are out of the scope of welfare economics -, the value confinement ideal - for which ethical values are acceptable if they are minimal and consensual-, the transparency requirement - for which any ethical values may be acceptable in the welfare economics framework if explicit and formalized -, and the entanglement claim which challenges the very possibility of demarcation between facts and values.
\end{abstract}

\section{Keywords:}

Welfare economics, facts and values, value judgement, welfarism, transparency, demarcation, normative and positive, neutrality

JEL codes:

B41, D60, D63

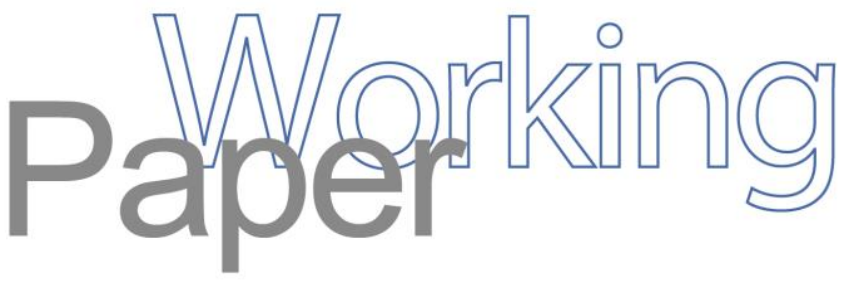




\title{
Values in Welfare economics ${ }^{1}$ \\ By Antoinette Baujard ${ }^{2}$
}

\begin{abstract}
This chapter focuses on the inner rationale and consequences of four different archetypal positions regarding how ethical and political values are tackled in welfare economics. Welfare economics is standardly associated with the welfarist framework, for which social welfare is based on individual utility only. Beyond this, we distinguish the value-neutrality claim - for which ethical values should be and are out of the scope of welfare economics -, the value confinement ideal - for which ethical values are acceptable if they are minimal and consensual-, the transparency requirement - for which any ethical values may be acceptable in the welfare economics framework if explicit and formalized -, and the entanglement claim - which challenges the very possibility of demarcation between facts and values.
\end{abstract}

Key-words. Welfare economics, facts and values, value judgement, welfarism, transparency, demarcation, normative and positive, neutrality

JEL Codes. B41, D60, D63

\section{Table of contents}

I- The value-neutrality claim

I-i) Objectivity

I-ii) Behaviourism

I-iii) The potential Pareto criterion

II- $\quad$ The value confinement ideal

II-i) A consensual focus on utility

II-ii) Welfarism

II-iii) Paretianism

III- The transparency requirement

III-i) Demarcation among a diversity of potential values

III-ii) The quantifying device of intersubjective neutrality

III-iii) Separation of tasks

IV- The entanglement claim

$I V$-i) The case of epistemic values

$I V$-ii) The contextual dependency of facts and values

1 This WP shall be published as a chapter of the Routledge Handbook of Philosophy of Economics, Conrad Heilmann \& Julian Reiss (Eds.) Routledge, 2023. This version has been accepted in February, 2021. I wish to thank Ben Young and Conrad Heilmann for their kind reading of this text. The usual caveat holds.

2 Univ Lyon, UJM Saint-Etienne, GATE UMR 5824, 42023 Saint-Etienne, France. Contact: antoinette.baujard@univ-st-etienne.fr. Orcid: 000-0002-4156-7527 
Welfare economics provides a general theoretical framework intended to be used to evaluate social states and to assist in public decision-making, with the underlying aim of improving social welfare. In terms of content, welfare economics draws heavily from microeconomics, which notably furnishes its two fundamental theorems, as well as the basis for cost-benefit or equity analyses. Welfare economics is thus used to evaluate the consequences of alternative situations or public policies as regards social welfare, generally considering social welfare as tightly linked to individual well-being.

The standard approach to social welfare in welfare economics is welfarist, i.e., social welfare is thought to depend only on individual utility and on no other information. It is fair to say that the term "welfarism"-notably introduced by Hicks (1959), and formally defined and popularized by Amartya Sen $(1977,1979 a, b)$ — was intended precisely as a tool to critique the use of welfarism in welfare economics; and there are indeed major issues in welfare economics connected to the welfarist framework, including the link between theory and practice, the definition of social welfare, and the foundations of the judgements used in welfare economics. While there exist a substantial number of distinct definitions of welfarism, each associated with specific lines of criticism or debate, philosophical approaches to welfare economics have in common the questioning of which information is to be judged relevant or legitimate for the determination of social welfare, and they seek in particular to tackle the hot issue of value judgements. The assessment of welfarism ultimately belongs to the wider debates regarding the axiological neutrality of sciences (see chapter ${ }^{3}$ on scientific objectivity, Reiss and Sprenger 2014), and the possibility of a demarcation between positive and normative economics (see chapter on positive and normative economics).

The present discussion hence focuses on whether welfare economics is a normative science, and how welfare economics should tackle normative objectives such as social welfare, given that promoting social welfare is its main end. As Atkinson (2009: 791) recalled, "economists frequently make judgments about economic welfare, but there is today little discussion of the foundations of welfare economics. It is assumed either that there is unanimity of interests, or that there is general acceptance of utilitarianism. This means that economics cannot address many key policy issues and that important differences in ethical views cannot be recognized." There are indeed several approaches to the issue of values in welfare economics, reflecting distinct lines of argumentation, and philosophical inquiry calls upon us to classify these approaches. Drawing on Mongin (2006), we here present and assess the principal positions on the spectrum between the extreme view that welfare economics is entirely neutral and the counterview that it is an entirely ideological practice. The aim is to set out what is at stake for each of these positions: rather than pretending there exist specific literatures corresponding to each of the views here canvassed, we instead focus on their inner rationales and key consequences. For the purposes of analysis, we single out for discussion four archetypal positions: value neutrality (section 1), the value confinement ideal (section 2 ), the transparency requirement (section 3), and the value entanglement claim (section 4). This classification is meant to help us better understand not only how the welfarist framework is defined and why it has been called into question, but more generally how each proposition in welfare economics fares with the issue of value neutrality, and how it tackles the problem of ethical value judgements.

\footnotetext{
${ }^{3}$ References to "chapters" are references to the content of the Handbook of Philosophy of Economics.
} 


\section{I-i) Objectivity}

Economics presents itself as a science in the mould of the natural sciences, and one of the objectivity requirements associated with such scientific ambition is that economics should be neutral with respect to judgements concerning ethical values. Seeing ethics as a matter of mere convention, subjectivity, or metaphysics, Robbins (1932) claims it is not liable to proof by observation or introspection, and he defends the influential view that ethics falls outside the scope of science - and hence of economics. In particular, there is no test that can be employed "in comparing the satisfaction of different people", and intercomparisons of utilities "cannot be justified by appeal to any kind of positive science", such that "it would be totally illegitimate to argue" that any recommendation may be warranted by economics: thus, he concludes, "propositions involving 'ought' are on an entirely different plane from propositions involving "is"” (Robbins 1932: 140-143). Economics should be neutral towards different ends and cannot pronounce on the validity of ultimate judgments of value (Robbins 1932: 147). The two areas of inquiry, economics and ethics, should therefore be considered disjoint, and at no time should economists hold ethical values.

\section{I-ii) Behaviourism}

The efforts of economics to establish itself as a value-neutral science has had deep and regrettable consequences for the conditions, the existence, and the reach of welfare economics. The exclusion of normative considerations and the focus on neutral observable phenomena have had direct consequences for the interpretation and the properties of individual utilities (Baujard 2017). Hedonic or moral utilities, in contrast with choices, are not observable. In revealed preference theory, utility is simply the numerical representation of choices, i.e. the ranking of alternatives derived from observed choice situations. Hence microeconomics, and subsequently welfare economics, has focused on utility under such a behavioural interpretation. Within such an interpretation, it is meaningless to talk about the intensity of utility or the comparison of utility between different individuals, such that welfare economics must as a consequence focus on ordinal and non-comparable utilities.

At the collective level, the only meaningful criteria for the ranking of social states at the collective level based on ordinal non-comparable utility is the Pareto criterion. ${ }^{4}$ According to the Pareto criterion, if everybody is at least equally better off in a state with the policy than without, and at least one individual is strictly better off with the policy, then the social state is better with the policy than without it. In every case where decisions may impact different individuals in a heterogenous way, i.e. where there are both losers and winners, welfare economics is not able to derive recommendations concerning whether the policy should be adopted. These situations are not comparable according to the Pareto criterion.

Thus, in most cases, the banishment of ethical values, and of interpersonal comparisons of utility in particular, automatically impedes the use of any normative premises, and hence any prescriptive assertions: no recommendations which enable us to decide among policies could be derived from an allegedly value-neutral welfare economics (Hicks 1939, Little 1950).

\footnotetext{
${ }^{4}$ Notice that, throughout the history of welfare economics, the Pareto criterion has been considered by economists both as a positive and as a normative view. Berthonnet and Declite (2014) have shown that its use evolved from a normative to a positive concept in the course of the second half of the 20th century.
} 


\section{I-iii) The potential Pareto criterion}

Welfare economics has not - to say the least - attained such a desired state of valueneutrality; yet nor did it remain content to debar itself from prescriptive judgement.

Kaldor (1939) and Hicks (1939) developed certain alternative methods in welfare economics designed to circumvent the preclusion of recommendations, appealing to the Weberian notion of the separation of the roles and tasks of politics and scientists. Imagine that losers lose less than winners win, and that transfers from the former to the latter are likely to elicit an improvement that may be unanimously acclaimed. In such a case, everybody is likely to be better off with the policy than without it, provided the transfers are actually implemented. Economists qua economists are able to assert that the policy is making a potentially universal improvement, while politicians are empowered to decide whether the transfers should or should not be effected. The separation of tasks between economists and politicians is here preserved, and recommendations may be proffered; but it is now questionable whether welfare economics still lives up to its ambition to issue recommendations without detouring through ethical judgements. "To say that a policy which meets the Kaldor-Hicks criterion increases the 'efficiency' of society is, in effect, to recommend it. Whereas if the value judgments implicit in the criterion are barred, it is unlikely to find favour with many people. [...] Compensation tests, consumers' and producers' surpluses suffer not only from the distributional complications common to comparisons based on such tests but also from difficulties in their measurement, largely owing to their essentially partial character" (Mishan 1960: 250-51). Some even conclude that, in its ambition to produce value-neutral recommendations, welfare economics should be considered as a failure (Chipman and Moore 1978: 548, 581).

From the perspective of the history of welfare economics, this debate on the place of ethical values within welfare economics has driven the evolution of the discipline from the old to the new welfare economics, and from welfare economics to contemporary theories of equity (Baujard 2017). But from a philosophical perspective these two observations should come as no surprise. As a consequence of Hume's guillotine, no recommendations can be formulated without normative premises, and hence value-neutrality impedes the very recommendations which were the raison d'être of welfare economics. Conversely, any recommendation must derive from some normative premises, hence the pretention of producing value-neutral recommendations is inconsistent. In so far as the aim of welfare economics is evaluation or recommendation, it is constrained to suppose that there is such a thing as a substantial notion of 'good' or 'better'.

Among the views which countenance normative premises in economics, we may distinguish two versions of an intermediate neutrality claim: the value confinement ideal and the transparency requirement.

\section{II- $\quad$ The value confinement ideal}

Rather than targeting the chimeric ambition of value-neutrality, economics may seek to associate itself with a value-free ideal, i.e. to seek to minimize the importance of ethical values on scientific reasoning. In practice, such a search for 'more' neutrality than 'less' amounts to confining oneself to a reduced number of ethical principles, which, although they are admittedly normative, should not generally be considered controversial. 


\section{II-i) A consensual focus on utility}

With the emergence of modern standard microeconomics in the interwar and Cold War periods, individual utility has come to be cautiously associated with subjective ordinal preferences. This concept of utility does not convey any substantial definition of well-being: it derives only from what individuals themselves judge to be relevant and valuable. This focus on subjectivity conforms with the respect for "consumer sovereignty" and manifests a strong resistance to paternalism (Amadae 2003, Desmarais-Tremblay 2020a,b), having emerged at a moment in history when freedom, individualism, and market competition appeared as the alternative to fascism and communism. Except for the individuals concerned, there is no reason why anybody should be entitled to say what is best for people. By trusting individuals' own ability to define their own version of well-being, economists would at least succeed in avoiding taking any stance in this regard themselves. Utility for microeconomics is defined in terms of subjective, ordinal, and non-comparable preferences; in order to fit with the value-containment ideal, welfare economics must also focus on this information. Note, however, that the assumption that subjective utility amounts to substantial well-being, or that it even satisfactorily reveals well-being, requires that individuals are sufficiently consistent, that their tastes and values are constant over the period studied, and that they are rational in seeking out the best strategies to serve their well-being. If these conditions are not met, as notably brought to light by behavioural economics, the assumption that subjective utility properly reveals real wellbeing remains debatable (see chapter on behavioural normative economics and the reconciliation problem).

\section{II-ii) Welfarism}

By focusing on individual utility, the value-containment ideal entails that welfare economics is welfarist, in the sense that the welfare of the community depends on the welfares of the individuals comprising it and on nothing else, with the further restriction that individual utility is nothing but the numerical representation of subjective ordinal non-comparable preferences. Under this definition, welfarism appears to be the only source of ethical values in welfare economics.

This implies, on the one hand, ethical individualism: a social state is assessed only on the basis of how that state affects individuals, to the exclusion of any other source of ethical values. We cannot assign an intrinsic importance to social phenomena, collective objects, or externalities apart from their individual parts.

On the other hand, welfarism supposes a stable focus on a given theory of individual utility. Welfare economics has long defended the superiority of subjective ordinal utility, instead of its alternative. But note that the selection of one notion of well-being could nevertheless be considered as a significant normative choice. Each notion is consistent with the formal welfarist framework, while also setting specific constraints upon it; it corresponds to distinct social theories of justice. Well-being could designate utility, ${ }^{5}$ or primary goods,

\footnotetext{
${ }^{5}$ Utility on the one hand may refer to a state of mind. Hedonic theories, as in classical Utilitarianism, consider well-being as the experience of happiness, the balance between pains and pleasures, or as flourishing. This notion of well-being has been seen as insufficiently measurable or comparable to be serviceable for the new welfare economics. An alternative is to see utility as the mere numerical representation of preferences: if individual $i$ prefers $x$ to $y$, this means her utility is higher with $x$ than with $y$. Under the revealed preference theory, $i$ prefers $x$ to $y$ if and only if she chooses $x$ when she has the opportunity to choose among $x$ and $y$. Philosophers would require that preferences be rational, informed, and based on true beliefs (see chapter on well-being, Hausman, and other issues on normative behavioural economics). When utility is interpreted on the basis of preferences alone, it is only ordinal and non-comparable. On the other hand, utility may refer to a state of the world, e.g. the level of
} 
resources, advantages, opportunities, capabilities, etc. (see section 3 in this chapter, and chapter on well-being)

Hence, within the value free-ideal, the normativity is imported not only through the use of the welfarist framework itself, but also in the choice of a given theory of well-being, insofar as there are indeed a number of alternative potential theories of well-being.

\section{II-iii) Paretianism}

Since welfare economics is required to derive recommendations at the collective level, there ought also to be a collective ethical principle besides that of welfarism. The Pareto criterion (strictly speaking) ultimately seems a reasonable candidate for the value containment claim, because it does not require any greater ethical load than the simple statement that improving individual well-being (whatever it is) is a good thing - and hence claims no more than welfarism as such (see next section on formal welfarism). Stating that individuals would be better off with than without a policy, with no losers, ought to be a matter of consensus, in so far as far as nobody has any reasonable interest in rejecting the claim and individual interest itself is considered as valuable.

However, since almost any public policy generates both losers and winners, adjudicating for or against the policy implies a trade-off between different parties with diverging interests. In such a context the Pareto criterion is mute, due to the exclusion of interpersonal comparisons, and more generally because of the exclusion of any further significant ethical commitment. Like the value-neutrality claim, the value-confinement claim fails to allow welfare economics to generate recommendations.

\section{III- The transparency requirement}

Any normative assertion requires some normative premises; in their absence, no recommendation may be formulated. Seeking neutrality, or even seeking more neutrality, in welfare economics is nothing but an illusion. And since value judgements are needed, the only alternative is to accept them as such, which first and foremost requires that we circumvent the difficulties induced by the role of values in economics.

Among the difficulties with the role of values in science-and economics is no exception in this regard - the possibility that the scientist's values might influence the outcome of her or his research is a significant source of scepticism about the reliability of scientific research outcomes. Considering that the scientist is only a specific individual, the potential role of her emotions, private interests, personal values, or illegitimate pressures may engender distrust of her particular scientific assertions. By contrast, scientific analysis is considered as reliable when assertions are void of any subjective bias on the part of those who formulate them. The goal of neutrality as regards values ought thus to be discarded; we should rather support the view that scientific assertions should be invariant to the individuality of different scientists.

The second difficulty with ethical values in science is that any debate on the desirability or appropriateness of ends for a society properly pertains to the role of elected officials within

individual income, the list of private goods and public amenities to which an individual has access, the number of kilometers that must be traversed in order to access water, etc. Such states may be described and measured similarly by different external observers. In this respect, capabilities appear to be an individual basis of information that is objectively measurable, albeit distinct for each individual, and which may be used as the individual well-being ingredient in the formal welfarist framework. 
the domain of politics (whose actors we may call politicians), rather than to the domain of science (whose producers we may call scientists, among whom number the economists). Science has no legitimacy to decide upon political values (e.g. Robbins 1932, Sugden 2008). As remarked in passing above, this echoes the famous thesis defended by Max Weber (1904) regarding the separation of tasks between politicians and scientists. However, given a set of political values given a priori, social science (and welfare economics in particular) may be able to provide insightful recommendations on the best strategies to reach the ends decided upon by politicians: economics "is incapable of deciding the desirability of different ends. [... ] It makes clear to us the implications of the different ends we may choose" (Robbins 1932: 152). The politicians' ends, once identified, should be able to be taken as given by economists. In other words, values should be given transparently by politicians and treated neutrally by scientists, such that any other set of scientists under the influence of different subjective biases would be able to derive the same conclusion.

As a provisional conclusion on this version of the non-neutrality view, there are three conditions which must be met for welfare economics to respect scientific standards while also engaging with value judgements: value transparency, intersubjective neutrality, and separation of tasks. The view deriving from these three requirements, which we call 'the transparency requirement', comes with certain consequences.

\section{III-i) Demarcation among a diversity of potential values}

Firstly, value judgments should be made transparent, not least because they are inescapable. Robbins (1932: 156) stated that, in the matter of policies, we need to choose among ends, and for this, "economics brings the solvent of knowledge. It enables us to conceive the far-reaching implications of alternative possibilities of policy. It does not, and it cannot, enable us to evade the necessity of choosing between alternatives". Little, for instance, also affirms that value judgments, and in particular judgments about distribution, whatever they are, cannot be avoided in welfare economics, but should at least be made explicit: "Since we believe that the essential purpose of the economics of wealth, happiness, or welfare is to make recommendations, and to influence people, it follows that it should be put on an explicit, and not merely an implicit value basis" (Little 1950: 116; see also Mishan 1960).

The transparency standard implicitly assumes there is a diversity of a priori equally acceptable ethical value judgements. The task of normative economics is "to examine the consequences of different ethical positions" (Atkinson 2009: 791). This definition manifests a sharp and acknowledged contrast with the common underlying suppositions that there may be welfare recommendations without any ethical commitments, that there exists such a thing as a consensual ethical position, or that we could rely on a more decisive ethical position, e.g. on the utilitarianism which is sometimes employed by economists without any debate or reflection. As Atkinson (2009: 803) remarks, "Many of the ambiguities and disagreements stem not from differences of view about how the economy works but about the criteria to be applied when making judgments [...] People can legitimately reach different conclusions because they apply

different theories of justice. This may seem self-evident to non-economists, but the economics profession in recent years has tended either to assume away welfare judgements or to assume that there is a general agreement"; and he goes on to regret "the disappearance from economics of discussion of the principles underlying normative statements" (Atkinson 2001: 193). Hence we first need to take for granted that there is a diversity of acceptable value judgements; the role of economics is to derive the subsequent recommendations and unveil the consequences of given value judgements. 
Diversity comes with the need to be explicit about which ethical judgement has been selected, and this requires the demarcation of facts and values. If demarcation were possible, we could then factor out the descriptive and the evaluative components, as suggested by Hare (1952). Yet certain judgements are not straightforwardly and exclusively prescriptive or evaluative: saying that some behaviour is 'rude' or 'cruel' entails both descriptive and evaluative judgements. Hare (1952), rather, proposed to consider such statements to be entirely descriptive, at least if we agree that we can judge an action to be rude, say, if it conforms to some pregiven norms of rudeness and politeness in society: we then need only describe such 'compliance' to the norm. Similarly, we could describe certain notions of fairness as equity, or of certain versions of utilitarianism, in terms of compliance to a norm, such that the consideration of these ethical values becomes just another descriptive ingredient included in our judgement. The transparency of values, then, is the other side of the demarcation claim.

\section{III-ii) The quantifying device of intersubjective neutrality}

Secondly, the means by which we make value judgements explicit should be introduced into economics in a manner which is itself neutral. Intersubjective neutrality may be obtained through devices that are able to formalize the normative criteria: this involves quantifying them, and, in particular, assigning a list of desirable normative criteria to these tools (and only to them).

Equity and welfare theories, henceforth called the "social welfare approach", have been developed in the context of the Bergson-Samuelson school of the New Welfare Economics, and in the wake of social choice theory. The social welfare approach seeks to analyse situations and rank them according to clear normative criteria (Adler 2019). Social welfare functions are tools in theoretical welfare economics, whose currency is not income or wealth but rather well-being and social welfare. The social welfare approach is characterized by two components: on the one hand, it assigns to each individual some inclusive measure of well-being, supposed to depend on every welfare-relevant dimension; for instance, well-being is defined as subjective utility, which ultimately depends on one's own consumption, or on opportunity or some objective index of well-being (see chapter on individual well-being). On the other hand, it provides a rule to rank these lists of measures at a collective level, taking into account a number of normative criteria of aggregation, e.g. utilitarian vs. egalitarian. This allows the policy analyst to represent and rank each possible outcome of a policy, for different contexts or for different alternative policy choices. Indeed, a social welfare function depends both on the normative choices concerning the relevant information about every individual's well-being, and on how to aggregate the list of individual well-beings into a collective judgment.

Allowing that some normative ingredients are amenable to being embedded within the tools of economics without importing any bias, the normative load of the social welfare function can then be assimilated to the ethical interpretation of those ingredients, typically as derived from some well-established philosophical theory. A specific approach today commonly called 'axiomatics', which is typical of normative economics, aims precisely at identifying these ingredients, and conversely, at choosing the proper devices given the desirable ingredients. At a high level of generality, axiomatics allows the deductive formalization of a given theory, whose propositions belong either to primary conditions called axioms or to derived propositions called theorems. Applied to welfare economics, it consists in the following steps: the primary conditions (including normative premises and descriptive elements) that collective evaluative rules should ideally satisfy are first captured by formal language; then we describe, by deduction, the logical consequences of the association of the different conditions, as the set of rules able to satisfy them exactly. If this set is empty, we have proven an impossibility result, 
which is itself interesting as a means to highlight the inconsistency of the desired conditions; if this set is not empty, there is a theorem which characterizes a solution.

The deductive part is either true or false: it can be proven or infirmed, but is not a matter of debate. The formal language does not convey any meaningful interpretation at all, at least until the axiomatics is given an external anchor point, e.g. an external theory able to make sense of the symbols (Mongin 2003: 101). Some premises, which should originate only from the politicians, may be value-laden, but their normativity is only conveyed, not transformed by the deductive process conducted by the scientist: "the axiomatization would allow us to disentangle the logical inference from the interpretations, and hence to exercise greater control over the latter than any other formalization process would" (Mongin 2003: 121, my translation). As a consequence of this clear separation of interpretation on the one hand, and formal deduction on the other, it becomes irrelevant who the scientist is, and the axiomatic approach is thus supposed to guarantee the neutrality of the treatment of the normative ingredients.

Just as Hare considered that 'rude' was only a descriptive judgement because it implied some compliance to the norm defining rudeness, Fleurbaey (1996) considers the axiomatic approach to welfare and equity as entirely positive in so far as it does not require any personal commitment from the researcher. For instance, this approach enables Fleurbaey, qua scientist, to explain the consequences of a utilitarian theory in a given context just as any committed utilitarian would do, although he, as a person, would certainly value a greater dose of egalitarianism.

\section{III-iii) Separation of tasks}

Thirdly, the transparency requirement supposes that the legitimacy of a given value judgement can differ depending on the perspective: judgements are of equal value from the scientific point of view, even while from the political point of view their value and social acceptability sharply varies.

The selection from among different potential normative criteria should not be done by scientists, but by those who have legitimacy to perform this function-hence either the persons themselves, or those who are representative of their interests (whom we above called politicians, after Weber). There is a diversity of possible views here, which formal devices may help us to objectivize and disentangle. In the archetypal transparency requirement, therefore, we observe a three-stage process of reasoning: politicians choose ethical values; scientists associate the politicians' values (and no others) within the social welfare functions through axiomatics; and policy analysts apply the chosen social welfare functions in the given context and derive normative conclusions. The use of axiomatics explicates the normative load of a chosen social welfare function; the application of this social welfare function to a specific situation then enables us to generate an evaluative or prescriptive judgement, which closely derives from the chosen values, but does not depend on the scientist. From this it follows that a similar situation may be judged differently by different philosophical theories, but equally by different analysts considering a given theory. A given sponsor may ask different scientists and still get the same 'neutral' answer to their normative question.

\section{IV- $\quad$ The entanglement claim}

The model offered by contemporary normative economics seems to meet the transparency requirement, although certain debates concerning the actual possibility of demarcation may still persist. Some, indeed, defend the thesis of an irreducible entanglement 
of facts and values; and as a consequence, the transparency of the normative load of any scientific assertion is not fully attainable, or will be potentially misleading.

\section{IV-i) The case of epistemic values}

According to Putnam (2002), values pervade scientific assertions. Descriptions always depend on the values or norms scientists may need to include in making their statements. He concludes that there is no such thing as a pure description of a reality waiting to be discovered by scientists, and that scientists' statements necessarily always include some normative content.

This recalls the argument made by Rudner (1953) that scientists are constrained to make value judgements: he underlines that "the scientist as scientist accepts or rejects hypotheses", which presupposes "the necessary selection of a confidence level or interval" (Rudner 1953: 2, 3 ), and hence the application of epistemic values. And this is indeed desirable, as it is the function of scientists in a society to uphold such epistemic value judgements. To fail to be aware of this is "to leave an essential aspect of the production of knowledge out of control", and hence what we need is a "science of ethics" (Rudner 1953: 6): "A science of ethics is a necessary requirement if science's progress toward objectivity is to be continuous. [...] A first step is surely comprised of the reflective self-awareness of the scientist in making the value judgements he must make."

Any tool that is able to make the values included in science transparent would be a positive step in the direction of building a science of ethics. This was precisely what was proposed in the previous section of this chapter: axiomatics is a device for transparency, and formal welfarism is the framework that allows a systematic analysis in welfare economics in particular. In formal welfarism we describe the normative content of an ethical claim on the basis of two ingredients: the normative choice of a theory of individual well-being on the one hand, and the normative choice of a specific aggregating device on the other. Fully describing the normative load of an assertion with no bias only holds conditionally upon the requirement that these two ingredients are independent of each other, however; otherwise, the dependency between the two levels would import other unexpected normative issues. ${ }^{6}$

And they are indeed not independent, since the aggregation rule enforces or requires certain properties of the informational basis: using a utilitarian sum requires cardinal utilities, and, conversely, ordinal utilities are compatible only with the Pareto criterion (Baujard 2017). Pursuing this line of thought, in providing a systematic analysis of this dependency for the case of voting rules, I have considered the individual informational basis as the voter's preferences as captured through a given form of ballot - which may be either the single name of a candidate, a list of approved names, names associated with nominal or cardinal grades for various given scales, etc.- - and the aggregative part as the aggregative component of the voting rule - which may be the sum, but also the mean or the median (Baujard 2015). While in a welfarist framework, the analysis of the normative load of a voting rule should be independently based on these two successive steps, I have shown that the ballot information depends on and influences the aggregative rule used through a mechanical effect, e.g. certain aggregative procedures are only compatible with certain forms of ballots. The dependency also obtains through psychological and behavioural effects: the strategic incentives or the ability for expression induced by the aggregative device, for instance, modifies the voter's expression of their preferences (see notably Baujard et al. 2018, Baujard et al. 2020); hence the ballot is not given independently of the voter's preferences, but also depends on the aggregative device.

${ }^{6}$ Gharbi and Meinard (2020) use a similar argument when, reflecting on the fact that formal welfarism has pretentions to neutrality, they maintain that the dependency of the two stages compromises this neutrality. 
As a consequence of the dependency between the two stages in formal welfarism, the possibility of demarcation is disrupted even in the case of axiomatics. Instead of concluding that there is an irreducible entanglement, some claim rather that it shifts the problem onward, and propose to modify the target of the axiomatic analysis: Ceron and Gonzalez (2020) propose to include the two levels simultaneously in their axiomatic analysis, and undertake a new research program in this regard. It is too early to say whether axiomatics may reveal itself to be the science of ethics that is likely to achieve a full normative analysis in this sense; but we can still assert that, as a device to factor out the descriptive and evaluative components of assertions at this stage, it is a good candidate to reduce the impact of the entanglement problem.

\section{IV-ii) The contextual dependency of facts and values}

Distinguishing between 'thick' and 'thin' concepts, Williams (1995) observes that thin judgement admits only evaluative content ('good' or 'bad', 'right' or 'wrong') and remains very general, while a thick concept combines evaluative and non-evaluative description ('cruel', 'generous', 'courageous') and implies some description of the context. But Williams also observes that such description can never be objective, as it always requires a perspective from which one wants to look at the world, ${ }^{7}$ hence he supports a relativistic thesis. Putnam (2002:34-45) questions his relativist conclusion, and rather supports the view that, because in thick concepts the evaluative and descriptive aspects are intertwined, there is an irreducible dependency between values and facts.

Sen (1967) insists on the importance of distinguishing 'compulsive' and 'noncompulsive' judgements among the diversity of value judgements. Compulsive judgements are imperative prescriptions, i.e. those that must be done whatever happens; non-compulsive evaluations are not absolutely obligatory, and may be neglected e.g. for lack of other potentially relevant information concerning the context. He then introduces a distinction between 'basic' and 'non-basic' statements. Some judgements may be basic if they always hold whatever the context: 'you should not kill, whatever happens'. Sen, however, very much doubts that any judgement can ever be considered as non-basic, and this doubt especially concerns those judgements likely to be relevant for welfare economics. Indeed it is hard to make sense of assertions such as: 'one should lower taxes, in every situation', or 'the local government should build a swimming pool, whatever the public finance and the tastes of the population'. By contrast, after a thorough descriptive analysis of the economic, social, and cultural situation, it may be meaningful to assert that 'in this specific case, it would serve aim $A$ or conform with value $B$ to lower taxes', or that 'considering the financial situation and the project, considering the cultural and sports policy goals of the new elected officials, considering the expected economic, social, and personal benefits of the pool set out in model $z$ of agency $\beta$, building a swimming pool would provide more social benefits than less'. As these examples illustrate, all evaluative statements depend in some sense on descriptive judgements. Conversely, descriptions are chosen based upon the specific aim of the value judgement embedded in the evaluation. Sen (1980) called this "description as choice", stating that any description supposes an active process of selection of some specific relevant information among an ocean of potentially relevant information. The description hence depends on this selection, which is driven by some values and goals.

Those values and goals should certainly not be swept under the carpet. They may even be specified as transparently as possible, as I have previously claimed in applying the

\footnotetext{
${ }^{7}$ By contrast, Sen $(1993,2009)$ considers this fact as the context for forming an objective positional view, at least if it can still be made context-dependent although personally invariant.
} 
"description as choice" argument to the axiomatic approach of formal welfarism (Baujard 2013). We said above that the use of axiomatics is able to strive towards being value-free as it conveys values which are not held by the scientist: this proposal might be acceptable if confined within a theory. Nevertheless, in the case of economics expertise, when applying the formal analysis to specific contexts experts need to include goals and values when describing relevant information concerning the context. The choice of description is intertwined with the choice of values. To go beyond the thesis of entanglement, therefore, we need not only a science of ethics but also a science of the art of choosing the right models and data in the context of expertise. This is yet to come; and until then, the entanglement claim, at least in so far as it concerns welfare economics in the making, still has a robust future.

\section{V- Conclusion}

Whether welfare economics is or is not value-laden is not a matter of debate: since welfare economics is not liable to issue in any recommendations without a prior reference to values, whether epistemic or ethical, it must be seen as pervaded with values. But depending on how the debate over ethical values has been approached-whether from the value confinement ideal, the value transparency requirement, or the entanglement claim - certain important restrictions and developments have taken place. Let us recognize that the neutrality claim is still very present in the economists' beliefs. The value confinement ideal has led to a strong restriction of focus to ordinal utilities, a narrowing of the number of value judgements, and, potentially, the silent inclusion of certain other ethical judgements. It is fair to say that the axiomatic devices elaborated in the transparency requirement as a means to make values transparent and clearly demarcate them from descriptive statements have not yet achieved generalized application in applied welfare economics; nevertheless, it seems to have constituted a first step in the reduction - if not the resolution - of the issues raised by the entanglement claim.

Now that we have established the different rationales as to how values may be considered within welfare economics, the major question for welfare economics - namely, what social welfare is - can be studied with fresh eyes. Being directly related to values, welfare economics is first required to define or decide what social welfare depends on, and which values should be considered as legitimate in this process. Choosing the relevant description of the social states entails an ethical commitment, which appears to be a fundamentally political issue. This chapter has intended to contribute to the clarification of the debate in this regard.

\section{Bibliography}

[1] ADLER, M. D. Measuring Social Welfare: An Introduction. Oxford University Press, 2019.

[2] Amadae, S. M. Rationalizing Capitalist Democracy : The Cold War Origins of Rational Choice Liberalism. University of Chicago Press, 2003.

[3] AtKinson, A. B. The strange disappearance of welfare economics. Kyklos 54 (2001), 193-206.

[4] AtKinson, A. B. Factor shares: the principal problem of political economy? Oxford Review of Economic Policy 25, 1 (03 2009), 3-16.

[5] Baujard, A. Value judgments and economics expertise. Working Paper GATE L-SE, WP 1314 (2013). (ftp ://ftp.gate.cnrs.fr/RePEc/2013/1314.pdflink).

[6] BAujaRD, A. Le bien-être et les valeurs en économie. Perspectives historique, expérimentale et philosophique, Mémoire d'Habilitation à diriger des recherches, Université de Lyon, 2015. 
[7] Baujard, A. L'économie du bien-être est morte. Vive l'économie du bien-être ! In Philosophie économique. Editions Matériologiques, 2017, ch. 2, pp. 77-128.

[8] Baujard, A., Gavrel, F., Igersheim, H., Laslier, J.-F., AND LebOn, I. How voters use grade scales in evaluative voting. European Journal of Political Economy 55 (2018), 14-28.

[9] Baujard, A., IgERsheim, H., AND LEBON, I. Some regrettable grading scale effects under different versions of evaluative voting. Social Choice and Welfare (2020), forthcoming.

[10] Berthonnet, I., AND DEClite, T. Pareto-optimality or pareto-efficiency: same concept, different names? an analysis over a century of economic literature. Research in the History of Economic Thought and Methodology (2014).

[11] Ceron, F., And Gonzalez, S. Approval voting without ballot restrictions. Theoretical Economics (2021), forthcoming.

[12] Chipman, J. S., AND Moore, J. C. The new welfare economics 1939-1974. International Economic Review (1978).

[13] Desmarais-Tremblay, M. W.H. Hutt and the conceptualization of consumers' sovereignty. Oxford Economic Papers 72, 4 (06 2020), 1050-1071.

[14] Desmarais-Tremblay, M. Paternalism and the public household. on the domestic origins of public economics. History of Political Economy (2021).

[15] Fleurbaey, M. Théories économiques de la justice. Economica, 1996.

[16] HicKs, J. Essays in world economics. The Clarendon Press, Oxford, 1959.

[17] HicKS, J. R. The foundations of welfare economics. Economic Journal 49 (december 1939), 696-712.

[18] KALDOR, N. Welfare propositions of economics and interpersonal comparisons of utility. Economic Journal 49 (september 1939), 549-552.

[19] Little, I. A critique of welfare economics. Oxford University Press, Oxford, 1950. 2nd ed. 1957.

[20] Mishan, E. J. A survey of welfare economics, 1939-1959. Economic Journal 70 (1960), 197-265. published in 1965 by MacMillan.

[21] Mongin, P. L'axiomatisation et les théories économiques. Revue Economique 54, 1 (2003), 99-138.

[22] Mongin, P. Value judgments and value neutrality in economics. Economica 72 (2006), 257-286.

[23] Putnam, H. The Collapse of the Fact/Value Dichotomy and Other Essays. Harvard University Press, Cambridge, 2002.

[24] REISS, J. The Philosophy of Economics : A Contemporary Introduction. Routledge, NY, 2013.

[25] ReISS, J., AND SPRENGER, J. Scientific objectivity. The Stanford Encyclopedia of Philosophy, Winter 2017. Edward N. Zalta (ed.), URL = <https ://plato.stanford.edu/archives/win2017/entries/scientific-objectivity/>.

[26] RobBins, L. An essay on the nature and significance of Economic Science, 1932(1984), 3rd ed. Macmillan, London.

[27] Rudner, R. The scientist qua scientist makes value judgments. Philosophy of Science 20, 1 (1953), 1-6.

[28] SEN, A. Internal consistency of choice. Econometrica 61, 3 (1993), 495-521.

[29] SEN, A. K. The nature and classes of prescriptive judgments. The philosophical quarterly 17, 66 (1967), 4262.

[30] SEN, A. K. On weights and measures: Informational constraints in social welfare analysis. Econometrica 45 (1977). Also in A. K. Sen, Choice, Welfare and Measurement, MIT Press, Cambridge, 1982.

[31] SEN, A. K. Personal utilities and public judgements: Or what's wrong with welfare economics? Economic Journal 89, 355 (septembre 1979), 537-558.

[32] SEN, A. K. Utilitarianism and welfarism. The Journal of Philosophy 76, 9 (1979), 463-489.

[33] SEN, A. K. Plural utilities. Proceedings of the Aristotelian Society 81 (1980-81), 193-215.

[34] SEN, A. K. The idea of justice. Harvard University Press, Cambridge (MA), 2009.

[35] Sugden, R. The opportunity criterion: consumer sovereignty without the assumption of coherent preferences. American Economic Review 94, 4 (2004), 1014-1033.

[36] Weber, M. Objectivity' in social science and social policy. In The Methodology of the Social Sciences. Free Press, 1904/1959.

[37] WiLliams, B. Truth in ethics. Ratio 8, 3 (1995), 227-236. 